3. Genkinger J.M., Spiegelman D., Anderson K.E. và công sư. (2009). ALCOHOL INTAKE AND PANCREATIC CANCER RISK: A POOLED ANALYSIS OF FOURTEEN COHORT STUDIES. Cancer Epidemiol Biomark Prev Publ Am Assoc Cancer Res Cosponsored Am Soc Prev Oncol, 18(3), 765-776.

4. Eisenhauer E.A., Therasse P., Bogaerts J. và cộng sự. (2009). New response evaluation criteria in solid tumours: Revised RECIST guideline (version 1.1). Eur J Cancer, 45(2), 228-247.

5. Wang Yi, Xiao Xiuying, et al. (2018), "A Survival Model in Locally Advanced and Metastatic Pancreatic Ductal Adenocarcinoma", Journal of Cancer, 9(7), pp. 1301-1307.

6. Heinemann V., Quietzsch D., Gieseler F. và cộng sự. (2006). Randomized phase III trial of gemcitabine plus cisplatin compared with gemcitabine alone in advanced pancreatic cancer. J Clin Oncol Off J Am Soc Clin Oncol, 24(24), 3946-3952.

7. Cunningham D., Chau I., Stocken D.D. và cô̂ng sự. (2009). Phase III randomized comparison of gemcitabine versus gemcitabine plus capecitabine in patients with advanced pancreatic cancer. J Clin Oncol Off J Am Soc Clin Oncol, 27(33), 5513-5518.

8. Colucci G, Roberto Labianca et al (2010), "Randomized phase III trial of Gemcitabine plus Cisplatin compared with Single-Agent Gemcitabine as First-line treatment of patients with advanced pancreatic cancer: The GIP-1 study", J Clin Oncol, 28, pp 1645-1651.

\title{
KẾT QUẢ PHẪU THUÂT U TUYẾN GIÁPLÀNH TÍNH TẠI BÊ̂NH VIỆN ĐẠI HỌC Y HÀ NộI
}

\section{TÓM TẮT}

Muc tiêu: Đánh giá kết quả phẫu thuật nội soi (PTNS) đường nách vú trong điêu tri u tuyến giáp lành tính tai Bệnh viên Đai học Y Hà Nô̂i. Đối tượng và phương pháp: Nghiên cứu mô tả hồi cứutrên 90 bệnh nhân chẩn đoán u tuyến giáp lành tính được phẫu thuât mở (45 bênh nhân) hoăc PTNS đường nách vú (45 bệnh nhân) cắt thùy hoặc cắt thùy và eo tuyễn giáp tại Bênh viên Đaii hoc Y Hà Nôi từ01/2019 đến 06/2019. Kết quả: Trung bình là $51,4 \pm 12,8$ tuổi

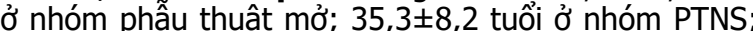
$91,1 \%$ nữ giới; tỳ lệ 1 u trên lâm sàng $80 \%$ ở nhóm phẩu thuât mở và $71,1 \%$ ở nhóm PTNS; u thùy phải $52,8 \%$ ở nhóm phẫu thuật mở và 59,4\% ở nhóm PTNS; kích thước u trung bình $25,9 \pm 10,1 \mathrm{~mm}$ ở nhóm phẫu thuật mở và $23,7 \pm 9,8 \mathrm{~mm}$ ở nhóm PTNS. Trên siêu âm, u TIRADS 3 chiếm $77,8 \%$ ở cả hai nhóm. Giải phẫu bệnh sau mổ bướu giáp keo chiếm $82,2 \%$ ơ nhóm phấu thuât mở và $84,4 \%$ ở nhóm PTNS. Cắt thuỳ tuyến giáp ở 73,3\% trường hợp trong nhóm phẫu thuật mở và ở 97,8\% trường hợ trong nhóm PTNS. Thời gian mổ trung bình $41,7 \pm 10,2$ phút ở nhóm phẫu thuât mở và $51,2 \pm 7,1$ phút ở nhóm PTNS; thời gian hậu phẫu $5,8 \pm 1,3$ ngày ở nhóm phẫu thuật mở và $6,0 \pm 1,2$ ngày ở nhóm PTNS. Không có trường hợp nào PTNS chuyển phâuu thuật mở. Không có biến chứng sau mổ ở nhóm phấu thuật mở, nhóm PTNS có 1 trường hợp $(2,2 \%)$ tu máu sau mổ, hết sau băng ép 1 ngày. Đau nhe sau mổ chiếm $62,2 \%$ trường hợp ở nhóm phẫu thuật mở và $82,2 \%$ trường hợp ở nhóm

\footnotetext{
${ }^{1}$ Trường Đại học Y Hà Nội

2Bênh viên Đai hoc Y Hà Nôi

Chịu trách nhiệm chính: Lê Văn Thắng

Email: lethanghmu@gmail.com

Ngày nhận bài: 2.8.2021

Ngày phản biên khoa họ: 1.10 .2021

Ngày duyệt bài: 8.10.2021
}

\section{Lê Văn Thắng1, Nguyễn Xuân Hậu ${ }^{2}$}

PTNS, không có trường hợp nào đau nặng sau mổ.0 bệnh nhân đánh giá không hài lòng về kết quả phẫu thuật, tî lệ rất hài lòng chiếm $75,6 \%$ ở nhóm phẫu thuất mở và $80 \%$ ở nhóm PTNS. Kết luân: Phẫu thuật mở và PTNS đường nách vú trong điều trị u tuyển giáp lành tínhtương đối an toàn, tỳ lệ tai biến, biến chứng thấp trong đó PTNS ít đau sau mổ hơn và đạt thẩm mỹ cao so với phẫu thuâtt mở.

Tư khóa: U giáp trạng, lành tính, phẫu thuật mở, phẫu thuật nội soi.

\section{SUMMARY \\ RESULTS OF THYROIDECTOMY FORBENIGN THYROID NODULEAT HANOI MEDICAL UNIVERSITY HOSPITAL}

Objective: Evaluate theearly results ofendoscopic thyroidectomy via unilateral axillo-breast approach (UABA) in the treatment of benign thyroid tumor at Hanoi Medical University Hospital. Subjects and Methods: Descriptive retrospective studies 90 patients with benign thyroid tumors were treated (lobectomy or lobectomy+ismuthsectomy) byopen thyroidectomy (45 patients) and byUABA (45 patients) at Hanoi Medical University Hospital from 01/2019 to $06 / 2019$. Results: Mean of age was $51,4 \pm 12,8$ years in the open thyroidectomy group; $35,3 \pm 8,2$ years in the UABA group. $91,1 \%$ patients were female. The solitary tumor occults $80 \%$ in the open thyroidectomy group and $71,1 \%$ in the UABA group;thethyroid tumors in the right lobe were $52,8 \%$ in the open thyroidectomy group and $59,4 \%$ in the UABA group; the average tumor size was $25,9 \pm 10,1 \mathrm{~mm}$ in the open thyroidectomy group and $23,7 \pm 9,8 \mathrm{~mm}$ in the UABA group. The tumors classified into TIRADS 3 by ultrasound was $77,8 \%$ in both groups. Most common pathology was colloid goitreaccounting for $82,2 \%$ in the open thyroidectomy group and $84,4 \%$ in the UABA group. Lobectomy was applied in $73,3 \%$ cases in the open thyroidectomy group and $97,8 \%$ cases in the 
UABA group. The mean operating time was $41,7 \pm 10,2$ minutes in the open thyroidectomy group and $51,2 \pm 7,1$ minutes in the UABA group, the mean hospitali zation was $5,8 \pm 1,3$ days in the open thyroidectomy group and $6,0 \pm 1,2$ days in the UABA group. There were no cases that changed from the UABA to the open thyroidectomy group. There was no postoperative complications in the open thyroidectomy group, in the UABA group there was 1 case $(2.2 \%)$ of postoperative hematoma, which resolved after 1 day of compression. Mild postoperative pain accounted for $62.2 \%$ of cases in the open thyroidectomy group and $82.2 \%$ of cases in the UABA group, there were no cases of severe postoperative pain in both groups. There were no patients that were not satisfied with the surgical results in both groups; $75,6 \%$ of cases were very satisfield in the open thyroidectomy group and $80 \%$ in the UABA group. Conclusions: Open thyroidectomy and endoscopic thyroidectomy via unilateral axillo-breast approachweresafe, the rate of complications was low, in which endoscopic thyroidectomy was less painful after surgery and achieved good cosmetic outcomes than open thyroidectomy.

Key words: Thyroid nodule,endoscopy thyroidectomy, UABA.

\section{I. ĐẶT VẤN ĐỀ}

U giáp trạng là bệnh lý phổ biến nhất của tuyến nội tiết. Theo tổ chức y tế thế giới, tỷ lệ mắc u giáp trạng là $12 \%$. Nữ giới có tỷ lệ mắc bệnh cao hơn nam giới, tỷ lệ nữ/ nam là 4/1[1]. Chẩn đoán dựa vào lâm sàng kết hợp với siêu âm vùng cổ và chọc hút tế bào bằng kim nhỏ khối u[2].

Phẩu thuật là phương pháp quan trọng nhất điều trị khối u giáp trạng. Hiện nay có hai phương pháp phẩu thuât là phấu thuật mở và phẫu thuật nội soi. Phẫu thuật nội soiđang trở nên phổ biến và được các phẫu thuật viên áp dụng theo nhiều đường tiếp cận.

Tại Việt Nam, phẫu thuật nội soi hoàn toàn cắt tuyến giáp tiếp cận đường nách vú được áp dụng từ 2003 tại Bệnh viện nội tiết trung ương, đến nay đã có nhiều cơ sở áp dụng phương pháp phẫu thuật nội soi trong đó có khoa Ung bướu và chăm sóc giảm nhẹ Bệnh viện Đại học Y Hà Nội. Tuy nhiên chưa có nghiên cứu nào đánh giá kết quả của 2 phương pháp này, do đó chúng tôi thực hiện đề tài này với mục tiêu sau:Đánh giá kết quả phẫu thuật nội soi đường nách vú trong điều trị u tuyến giáp lành tính tại Bệnh viện Đại học $Y$ Hà Nội.

\section{II. ĐỐI TƯỢNG VÀ PHƯƠNG PHÁP NGHIÊN CỨU}

1. Đối tượng nghiên cứu. Gồm 90 bệnh nhân được chẩn đoán u giáp trang lành tính và được phẫu thuật mở hoặc phẫu thuật nội soi đường nách vú cắt thùy hoặc cắt thùy và eo tuyến giáp tại Bệnh viện Đại học Y Hà Nội. Thời gian thực hiện nghiên cứu từ 01/2019 đến tháng 06/2019.

\subsection{Tiêu chuẩn chọn bênh nhân.}

- Bệnh nhân u tuyến giáp chẩn đoán trước mổ lành tính dựa vào siêu âm vùng cổ và tế bào học qua chọc hút bằng kim nhỏ.

- Chon u:

$\checkmark$ Trường hợp một u: Kích thước lớn nhất của $\mathrm{u} \leq 5 \mathrm{~cm}$.

$\checkmark$ Trường hợp nhiều u: Các u ở một thùy hoặc một thùy và eo giáp, kích thước thùy giáp $<6 \mathrm{~cm}$.

\subsection{Tiêu chuẩn loại trừ:}

- Tiền sử phấu thuật, xạ trị vùng cổ.

- Tình trạng viêm cấp tính toàn thân hoặc tại tuyến giáp, tuyến vú bên phẫu thuật.

- Có chống chỉ định chung của phẫu thuật, gây mê hồi sức: bất thường chúc năng đông máu, bệnh mạn tính toàn thân, thể trạng kém.

2. Phương pháp nghiên cứu: Nghiên cứu mô tả hồi cứu

\section{Phương pháp thu thập số liệu}

3.1.Đặc điểm lâm sàng: Tuổi; giới; lý do vào viện; khám u: vị trí u (thùy phải, thùy trái, eo), số lượng u, kích thước u (cm), mật độ u (mềm hay cứng, chắc), ranh giới u (rõ hay không rõ), di động u (có hay không có di động).

3.2. Cận lâm sàng: Siêu âm tuyến giáp đánh giá: số lượng u, phân loại TIRADS; vị trí u (thùy phải, thùy trái, eo), kích thước u.

\subsection{Phương pháp phấu thuật mở tuyên giáp}

$\checkmark$ Phương pháp vô cảm: mế nội khí quản

$\checkmark$ Dụng cụ phấu thuật: dụng cụ phâuu thuật mở, dao siêu ẩm, dao điện.

$\checkmark$ Tư thế bệnh nhân: Bênh nhân nằm ngửa, kê gối vai ngửa cổ tối đa. 2 tay khép.

$\checkmark$ Các bước phẫu thuật:

- Rạch da ngang nếp lằn cổ dưới, cách hõm ức khoảng hai khoát ngón tay, cắt cơ bám da cổ, bóc tách hai vạt da lên trên và xuống dưới. Mở dọc qua cân cổ trước khí quản, bộc lộ rõ thùy tuyến giáp chứa khối u.

- Phẫu tích bộc lộ động mạch giáp trên và giáp dưới. Sử dụng dao Ligasure cắt động mạch theo thứ tự.

- Tìm và bộc lộ các tuyến cận giáp và thần kinh thanh quản quặt ngược.

- Tiến hành cắt tuyến giáp phụ thuộc vào chỉ định điều trị: cắt thùy tuyến giáp, cắt thùy và eo tuyến giáp.

- Kiểm tra, cầm máu.Đóng cân cơ, đóng da theo các lớp giải phẫu.

$\checkmark$ Các chỉ số phẫu thuật: Thời gian phẫu 
thuật, thời gian hậu phẫu, đau sau mổ; tai biến, biến chứng: khàn tiếng, chảy máu, tụ máu, hạ canxi máu, nhiễm trùng; mức độ hài lòng.

3.4. Phương pháp phẫu thuật nội soi tuyến giáp đường nách vú 1 bên

$\checkmark$ Phương pháp vô cảm: mê nội khí quản

$\checkmark$ Dụng cụ phẫu thuật: Dàn máy nội soi, dụng cụ nội soi, dao siêu âm nội soi, dao điện.

$\checkmark$ Tư thế bênh nhân: Bệnh nhân nằm ngửa, kê gối vai ngửa cổ tối đa, cổ quay về phía thùy giáp lành. Tay cùng bên dạng tối đa để bộc lộ rõ vùng hố nách, tay đối diện dạng vuông góc thân mình.

$\checkmark$ Các bước phẫu thuật:

- Đặt troca: Troca 10 được đặt tại đường nách giữa ngang với bờ trên tuyến vú, 1 troca 5 đặt ở rãnh delta ngực cùng bên, 1 troca 5 đặt ở quầng vú cùng bên.

- Tạo khoang phẫu thuật: Dùng đơn cực bóc tách lởp dưới da vùng ngực đến vùng cổ đến ngang sụn giáp, sang hai bên đến cơ ức đòn chũm.

- Tách cơ vào tuyến giáp: Tách bờ trước cơ ức đòn chũm ra ngoài, cơ vai móng lên trên ra ngoài, tách dọc cơ ức giáp để vào tuyến giáp.

- Đánh giá tổn thương để đưa ra hướng phẫu thuật: Cắt thùy giáp, cắt thuỳ và eo tuyến giáp.

- Chú ý trước khi cắt thùy giáp bộc lộ rõ thần kinh quặt ngược và tuyến cận giáp để bảo tồn.

- Kiểm tra và lấy bệnh phẩm

$\checkmark$ Các chỉ số phẫu thuật: Thời gian phẫu thuật, thời gian hậu phẫu, đau sau mổ; tai biến, biến chứng: khàn tiếng, chảy máu, tụ máu, hạ canxi máu, tê bì vùng ngực, nhiễm trùng; mức độ hài lòng.

\section{KẾT QUẢ NGHIÊN CỨU}

\section{1. Đặc điểm lâm sàng, cận lâm sàng.} Tuổi

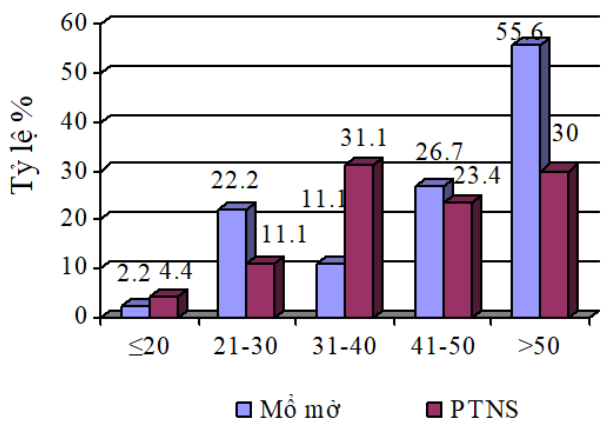

Biểu đồ 1. Phân chia nhóm tuổi

Tuổi trung bình là $51,4 \pm 12,8$ tuổi ở nhóm

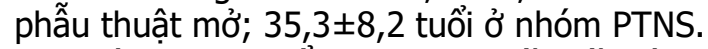

Nhóm > 50 tuổi hay gặp nhất đối với nhóm phẫu thuật mở chiếm 55,6\%; nhóm 31 - 40 tuổi hay gặp nhất đối với nhóm PTNS chiếm 31,1\%.
Giới: 2 nhóm đều có tỉ lệ nữ $91,1 \%$.

Lý do vào viện: Sờ thấy u vùng cổ hay gặp nhất ở nhóm phẫu thuật mở chiếm $55,6 \%$. Không có triệu chứng cơ năng hay gặp nhất ở nhóm PTNS chiếm 35,6\%.

Đặc điểm u trên lâm sàng: Tỉ lệ sờ thấy u khi khám lâm sàng là $80 \%$ ở nhóm phẫu thuật mở và $71,1 \%$ ở nhóm PTNS.

Tỷ lệ sờ thây 1 u trên lâm sàng $72,2 \%$ ở nhóm phẫu thuật mở và $96,1 \%$ ở nhóm PTNS xét trong số trường hợp khám sờ được u trên lâm sàng.

$\mathrm{U}$ ở thùy phải chiếm tỉ lệ cao nhất chiếm $52,8 \%$ ở nhóm phẫu thuật mở và $59,4 \%$ ở nhóm PTNS. Tất cả các u khi sờ thây đều có mật độ mềm và di động với xung quanh.

\section{Siêu âm}

Bảng 1. Đặc điểm u qua siêu âm

\begin{tabular}{|c|c|c|c|}
\hline \multicolumn{2}{|c|}{ Đặc điểm u } & $\begin{array}{c}\text { Mố mở } \\
\text { n (\%) }\end{array}$ & $\begin{array}{c}\text { PTNS } \\
\text { n (\%) }\end{array}$ \\
\hline \multirow{4}{*}{ Vị trí } & Thùy phải & $\mathbf{2 4 ( 5 3 , 3 )}$ & $\mathbf{2 6 ( 5 7 , 8 )}$ \\
\cline { 2 - 4 } & Thùy trái & $9(20)$ & $18(40)$ \\
\cline { 2 - 4 } & Thùy trái+eo & $5(11,1)$ & $1(2,2)$ \\
\cline { 2 - 4 } & Thùy phải+eo & $7(15,6)$ & 0 \\
\hline \multirow{3}{*}{$\begin{array}{c}\text { Thành } \\
\text { phân }\end{array}$} & Dịch & $4(8,9)$ & $6(13,3)$ \\
\cline { 2 - 4 } & Hôn hợp & $\mathbf{3 5 ( 7 7 , 8 )}$ & $\mathbf{3 3 ( 7 3 , 4 )}$ \\
\cline { 2 - 4 } & Đặc & $6(13,3)$ & $6(13,3)$ \\
\hline
\end{tabular}

Về số lượng u: nhóm phấu thuật mở số bệnh nhân nhiều u chiếm đa số $68,9 \%$; nhóm PTiNS số bệnh nhân 1 u chiếm đa số với $77,8 \%$. Về phân loại TIRADS 2011, các khối u xếp loại TIRADS 3 chiếm tỷ lệ 77,8\% ở cả 2 nhóm; các khối u xếp loại TIRADS $4 a$ chiếm $20 \%$ ở nhóm phẫu thuật mở và $13,3 \%$ ở nhóm PTNS. Về kích thước u: kích thước u trung bình là 25,9 - 48)mm đối với nhóm phẩu thuâtt mở và $23,7 \pm$ 9,8 (8-50) mm đối với nhóm PTNS; nhóm u có kích thước từ 2 đến $4 \mathrm{~cm}$ chiếm tỷ lệ cao nhất $66,7 \%$ và $53,4 \%$ lần lượt với nhóm phẫu thuật mở và PTNS.

\section{2. Điêu trị}

Thời gian và phương pháp phẫu thuật. Thời gian mổ trung bình là $41,7 \pm 10,2$ (30-60) phút ở nhóm phẫu thuật mở và $51,2 \pm 7,1$ (4065) phút ở nhóm PTNS.

Bảng 2.Phương pháp phẫu thuật

\begin{tabular}{|c|c|c|}
\hline $\begin{array}{c}\text { Phương pháp phâu } \\
\text { thuật }\end{array}$ & $\begin{array}{c}\text { Mố mở } \\
\text { n(\%) }\end{array}$ & $\begin{array}{c}\text { PTNS } \\
\text { n(\%) }\end{array}$ \\
\hline Cắt thùy tuyến & $33(73,3)$ & $44(97,8)$ \\
\hline Cắt thùy và eo tuyến & $12(26,7)$ & $1(2,2)$ \\
\hline
\end{tabular}

Thời gian nằm viện và đau sau mổ 
Thời gian nằm viện sau mổ trung bình là $5,8 \pm 1,3$ (3-8) ngày ở nhóm phẫu thuật mở và $6,0 \pm 1,2$ (4-9) ngày ở nhóm PTNS.

\section{Bảng 3. Đau sau mổ}

\begin{tabular}{|c|c|c|c|}
\hline $\begin{array}{c}\text { Mức độ } \\
\text { đau }\end{array}$ & $\begin{array}{c}\text { Mố mở } \\
\mathbf{n ( \% )}\end{array}$ & $\begin{array}{c}\text { PTNS } \\
\mathbf{n ( \% )}\end{array}$ & p \\
\hline Đau nhẹ & $\mathbf{2 8 ( 6 2 , 2 )}$ & $\mathbf{3 7 ( 8 2 , 2 )}$ & \multirow{2}{*}{$<$} \\
\cline { 1 - 3 } Đau vừa & $17(37,8)$ & $8(17,8)$ & 0,001 \\
\hline Đau nặng & 0 & 0 & \\
\cline { 1 - 2 } & & & \\
\cline { 1 - 2 }
\end{tabular}

Kết quả phấu thuật. Nhóm phẫu thuật mở không xảy ra tai biến trong phẫu thuật và biến chứng sau phẫu thuật. Nhóm PTNS khổng xảy ra tai biến trong phẫu thuật; biến chứng sau phẫu thuật có 1/45 trường hợp tụ máu chiếm 2,2\%; xử trí băng ép.

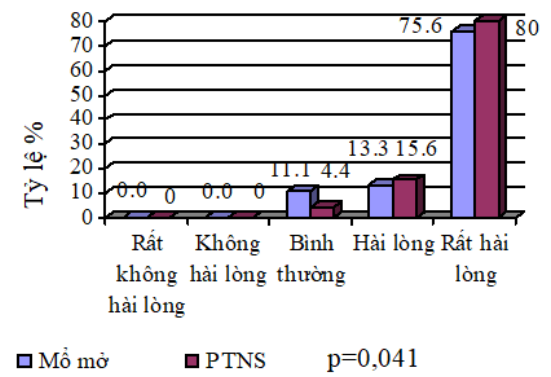

Biểu đồ 2. Mức độ hài lòng sau mổ

\section{BÀN LUÂ̂N}

\section{1. Đặc điểm lâm sàng, cận lâm sàng}

Tuổi, giới. Tuổi trung bình của bệnh nhân trong NC của chúng tôi là 51,4 tuổi ở nhóm phẫu thuật mở cao hơn so với tuổi trung bình của nhóm PTNS là 35,3 tuổi, $(p<0,001)$. Kết quả này cũng tương đồng với kết quả NC của Trịnh Minh Tranh (2013) trên 307 BN trong đó có 106 BN mổ mở và 201 BN PTNS thì tuổi trung bình của nhóm mổ mở là 40,2 tuổi cũng cao hơn tuổi trung bình của nhóm PTNS là 32,5 tuổi[3]. Điều này có thể lý giải là do các $\mathrm{BN}$ trẻ tuổi thường có nhu cầu về mặt thẩm mỹ cao nên ưu tiên lựa chọn phương pháp PTNS.

Cả nhóm mổ mở và nhóm PTNS đều có tỉ lệ nữ giới là $91,1 \%$ và nam giới là $8,9 \%$. Theo NC của Trịnh Minh Tranh, nhóm mổ mở có tỉ lệ nữ là $81,1 \%$ và nhóm PTNS có tỉ lệ nữlà $92,5 \%$ [3]. Nhìn chung tỉ lệ mắc u giáp ở nữ giới chiếm đa số.

Triệu chứng lâm saing. Đa số bệnh nhân ở nhóm phẫu thuật mở đên viện với lý do xuất hiện u giáp đợn thuần chiếm tỷ lệ cao nhất $(55,6 \%)$. Trong NC về phẫu thuât mở của Lê Văn Giáp (2014) tỷ lệ có u vùng cổ là 93,7\%[4]. Ở nhóm PTNS thì lý do vào viện chiếm tỉ lệ cao nhất là phát hiện u qua siêu ẩm khám sức khỏe chiếm $35,6 \%$. Theo tác giả Hershman và Blahd
(2005), tỉ lệ bệnh nhân đến viện có tới 15,2\% là chỉ tình cờ phát hiện qua khám sức khỏe[5].

Tỉ lệ sờ thây u khi khám lâm sàng là $80 \%$ ở nhóm phẫu thuật mở và $71,1 \%$ ở nhóm PTNS. Kết quả của chúng tôi gần tương tự nghiên cứu của tác giả Đinh Xuân Cường (2010) là 96,4\%[6].

Siêu âm tuyến giáp. Trong nghiên cứu này, siêu âm phát hiện được $100 \%$ có u tuyến giáp. Nhóm phẫu thuật mở tỉ lệ một u chỉ có $31,1 \%$ trong khi đó nhóm PTNS tỉ lệ một u là 77,8\%. Vị trí u hay gặp là thùy phải chiếm 53,3\% ở nhóm phẫu thuật mở và $57,8 \%$ ở nhóm PTNS. Về kích thước u: kích thước u trung bình là 25,9 $9 \pm 10,1$ (7 - 48) $\mathrm{mm}$ đối với nhóm phẫu thuật mở và 23,7 \pm 9,8 (8-50) mm đối với nhóm PTNS; nhóm u có kích thước từ 2 đến $4 \mathrm{~cm}$ chiếm tỷ lệ cao nhất $66,7 \%$ và $53,4 \%$ lần lượt với nhóm phẫu thuật mở và PTNS. Hiện nay, tại Bệnh viện Đại học $Y$ Hà Nội đang áp dụng phương pháp đánh giá kết quả siêu âm tuyến giáp theo TIRADS, trong nghiên cứu của chúng tôi tỷ lệ gặp nhiều nhất là TIRADS 3 với 77,8\% ở cả 2 nhóm. Dựa vào phân loại theo TIRADS, người ta ước tính được nguy cơ ác tính của khối u tuyến giáp (ví dụ: TIRADS $4 a$ là $20 \%$, 4b là $40 \%$, 4c là $60 \% \ldots$...

\subsection{Kết quả điêu trị}

Phương pháp phẫu thuật. Trong nghiên cứu này, phần lớn bệnh nhân được phẫu thuật cắt thùy giáp chứa khối u chiếm $73,3 \%$ ở nhóm phẫu thuật mở và $97,8 \%$ ở nhóm PTNS. Có $26,7 \%$ bệnh nhân ở nhóm phẫu thuật mở và chỉ có $2,2 \%$ bênh nhân ở nhóm PTNS được cắt thùy và eo giáp trạng. Sở dĩ chúng tôi phẫu thuật cắt cả eo tuyến giáp là do trong một số trường hợp u nằm ở vị trí sát eo giáp trạng.

Thời gian phẫu thuật và thời gian hậu phẫu. Thời gian phẫu thuật trung bình là

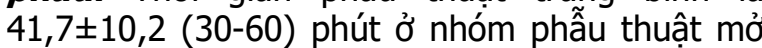
và $51,2 \pm 7,1(40-65)$ phút ở nhóm PTNS. Đối với mổ mở, trung bình thời gian mổ trong nghiên cứu này thấp trong nghiên cứu của Trịnh Minh Tranh (2013) là 75,7 phút[3]. Đối với PTNS, thời gian phẫu thuật của chúng tôi cao hơn nghiên cứu của Trần Ngoc Lương là 40 phút[7].

Trung bình số ngày nằm viện sau phẫu thuật mở là 5,8 $\pm 1,3$ ngày; sau phẩu thuật nội soi là $6,0 \pm 1,2$ ngày. Theo Trịnh Minh Tranh (2013) nhóm mổ mở và nhóm phẫu thuật nội soi có trung bình thời gian nằm viện sau mổ đều là 3,6 ngày[3].

Biến chứng sau mô. Trong nghiên cứu này có 1 bệnh nhân bị tụ máu sau mổ $(2,2 \%)$, xử trí băng ép không phải mổ lại. Ngoài ra không phát hiện có các biến chứng khác như: khán tiếng, hạ 
canxi máu. Mức độ đau sau mổ được chia thành các mức: đau nhẹ, đau vừa và đau nặng. Kết quả nghiên cứu của chúng tôi trong 24 giờ sau mổ mức độ đau của bệnh nhân gặp nhiểu nhất là đau nhẹ chiếm $62,2 \%$ đối với mổ mở và $82,2 \%$ đối với phẫu thuật nội soi $(p<0,05)$.Trong nghiên cứu của Trịnh Minh Tranh (2013) nhóm phẫu thuật mở có tỷ lệ đau vừa là $62,3 \%$ và đau nhe là 14,2\%; nhóm PTNS có tỉ lệ đau nhe là 85,6\%[3]. Trong nghiên cứu của Lê Văn Giáp (2014) về phẫu thuật mở thì tỷ lệ đau nhe là $10 \%$ và đau vừa là $90 \%$ [4]. Có thể thây PTNS đau sau mổ ít hơn so với phẫu thuật mở. Tỷ lệ rất hài lòng về kết quả điều trị ở nhóm PTNS $(80 \%)$ cao hơn ở nhóm phẫu thuật mở $(75,6 \%)$, $(p<0,05)$. Trong nghiên cứu của Trịnh Minh Tranh (2013) có 94,6 \% bệnh nhân hài lòng đối với nhóm PTNS, tỷ lệ này ở nhóm phẫu thuật mở là 76,4\%[3]. Trong nghiên cứu về PTNS tuyến giáp của Akira (2008) có $96,4 \%$ bệnh nhân hài lòng về kết quả điều trị[8]. Có thể thấy bệnh nhân ở nhóm PTNS hài lòng hơn về kết quả điều trị so với nhóm phẫu thuật mở, đặc biệt là vấn đề thẩm mỹ.

\section{KẾT LUÂ̂N}

Phẫu thuật mở và PTNS đường nách vú đều có thể áp dụng trong điều trị u tuyến giáp lành tính với tính hiệu quả và độ an toàn cao, tỉ lệ tai biến trong mổ và biến chứng sau mổ thấp. Trong đó PTNS đường nách vú đảm bảo yêu cầu về thẩm mĩ ngày càng cao của bệnh nhân đồng thời mức độ đau sau mổ ít hơn so với phẫu thuật mở.

\section{TÀI LIÊUU THAM KHẢO}

1. Tunbridge W.M., Evered D.C., Hall R., et al. (1977). The spectrum of thyroid disease in a community: the Whickham survey. Clin Endocrinol (Oxf), 7(6), 481-493.

2. Gharib H, Papini E, Garber JR, et al (2016). American Association of Clinical Endocrinologists, American College of Endocrinology, and Associazione Medici Endocrinologi 'Medical Guidelines for Clinical Practice for the Diagnosis and Management of Thyroid Nodules - 2016 Update Appendix. Endocrine Practice, 22,1-60.

3. Trinh Minh Tranh (2013), Nghiên cứu chỉ định điểu trị bướu giáp đơn nhân bằng phẫu thuâtt nôi soi, Luận án tiến sỹ Y học, Đại học Y dược tp Hồ Ċhí Minh.

4. Lế Văn Giáp (2014), Nghiên cứu đăc điểm lâm sàng, cận lâm sàng và đánh giá kểt quả phẫu thuật u lành tính một thùy tuyên giáp qua đường cổ bên, Luân văn Thạ́ sĩ Y học, Đai học Y Hà Nôi, HN.

5. Hershman J. M. (2005). Perchlorate and thyroid function: what are the environmental issues?. Thyroid: official journal of the American Thyroid Association, 15(5), 427-431.

6. Đinh Xuân Cường (2004). "Nghiên cứu đặc điểm lâm sàng, mô bệnh học và kết quả điều trị phẩu thuật ung thư tuyến giáp tại bệnh viện $\mathrm{K}^{\prime \prime}$. Luân văn thạc sĩ y hoc, Hà Nội, 33 - 48.

7. Trần Ngọc Lương (2011). Đ̇ánh giá kết quả phẫu thuật nội soi điêu trị bướu giáp lành tính. Tạp ch phẩu thuật nội soi và nội soi Việt Nam. 1(2), 20-24.

8. Sasaki A, Nakajima J, Ikeda K, Otsuka K, Koeda K, Wakabayashi G (2008). Endoscopic Thyroidectomy by the Breast Approach: A Single Institution's 9-year Experience. World journal of surgery, 232,381-385.

\section{HOÀN THIỆN QUY TRÌNH XA TRI LẬP THỂ TRÊN HỆ PHANTOM SỬ DỰG MÁY GIA TỐC VERSA-HD TẠI BỆNH VIỆN K}

\section{TÓM TẮT}

Mục tiêu: Xa trị lập thể trên nền tảng máy gia tốc tuyến tính là một lựa chọn tối ưu cho những bệnh nhân có chỉ định điều trị. Mỗi cơ sở được trang bị hệ thống máy và thiết bị phụ trợ khác nhau. Nghiên cứu triển khai thực hiện xạ trị lập thể trên hệ phanton hình đâu người để bưởc đẩu chuẩn hóa quy trình xạ trị lập thể trên nền tảng máy gia tốc tuyến tính VersaHD tại bệnh viện $K$. Đối tượng và phương pháp nghiên cứu: Nghiên cứu thực hiện dựa trên các hướng dẫn

\section{${ }^{1}$ Bệnh viện $K$}

Chịu trách nhiệm chính: Lê Văn Tình

Email: tinhbvk@gmail.com

Ngày nhận bài: 4.8.2021

Ngày phản biên khoa họ: 1.10 .2021

Ngày duyệt bài: 8.10.2021
Lê Văn Tình ${ }^{1}$, Nguyễn Thị Thơm ${ }^{1}$, Nguyễn Thanh Bình ${ }^{1}$

quốc tế của ICRU và AAPM về quy trình lập kế hoạch và đánh giá kế hoạch. Ngoài ra, nghiên cứu thực hiện quy trình xạ trị lập thể trên phantom giả lập đầu người với kích thước và vị trí u khác nhau. Kết quả: Đưa ra quy trình lâp kế hoach và đánh giá kế hoach xa tri tai cơ sở, đánh giá được khả năng thực thi của cắc thiết bị hiện có tai cơ sở trong việc thực hành xa phấu. Kết luận: Nghiển cứu khẳng định khả năng thực hiện kĩ thuật xạ phẫu trên nền tảng máy gia tốc và các thiết bị đi kèm của cơ sở trước khi thực hiện điêuu trị trên bệnh nhân.

\author{
SUMMARY \\ STEREOTACTIC RADIATION THERAPY \\ PROCESS ON PHANTOM SYSTEM USING \\ VERSA-HD LINEAR ACCELERATOR AT \\ VIETNAM NATIONAL CANCER HOSPITAL
}

